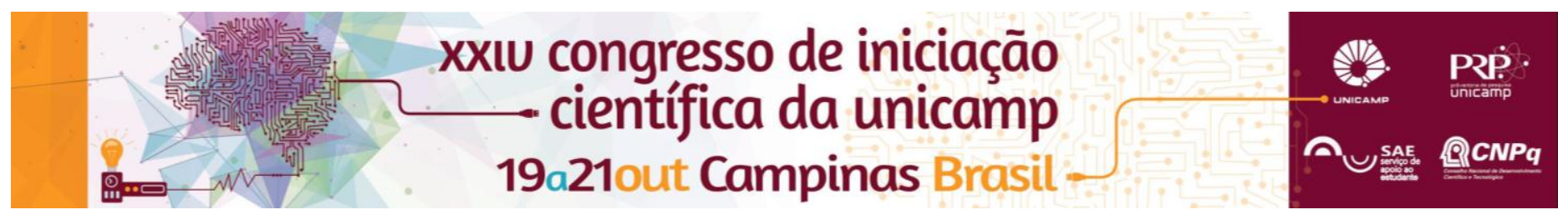

\title{
LEITURA, ESCRITA E TECNOLOGIA ASSISTINA NA BAIXA VISÃO: UM ESTUDO DE CASO
}

\author{
Antonio Lucas Goncalves Rodrigues*, Maria Elisabete R. F. Gasparetto
}

\section{Resumo}

O sujeito com baixa visão enfrenta certa dificuldade para inserir-se e sentir-se pertencente a uma sociedade majoritariamente despreparada para sua devida inclusão. Nesse sentido, o objetivo deste trabalho é relatar o uso de recursos de tecnologia assistiva por dois sujeitos com baixa visão, que necessitavam realizar treinamento com recursos ópticos e eletrônicos.

\section{Palavras-chave}

Leitura e escrita; baixa visão; tecnologia assistiva.

\section{Introdução}

O mundo em que vivemos é um lugar marcado pelas percepções visuais. A leitura é uma habilidade crucial na sociedade, necessitando da integridade do sistema visual e das funções corticais superiores. Para o reconhecimento das letras é necessário apenas uma área limitada do campo visual, no entanto, a leitura de palavras requer um campo visual maior, dificultando a leitura e a escrita de pessoas com baixa visão ${ }^{1}$. Por essa razão, o sujeito com baixa visão enfrenta certa dificuldade para inserir-se e sentir-se pertencente a uma sociedade majoritariamente despreparada para a sua comunicação e inclusão. O objetivo deste trabalho foi relatar o uso de recursos de tecnologia assistiva por dois sujeitos participantes do Programa de Habilitação e Reabilitação para pessoas com deficiência visual de um Serviço Unniversitário de Campinas, São Paulo, que foram encaminhados para realizarem treinamento com recursos ópticos, não ópticos e eletrônicos.

\section{Resultados e Discussão}

Utilizou-se a abordagem metodológica do estudo de caso. Participaram do estudo dois sujeitos com baixa visão que haviam sido encaminhados para realizarem um treinamento com a lupa eletrônica, com os óculos e com a lupa manual. O primeiro deles é um adulto e apresenta baixa visão por neurite óptica bilateral associada à hidrocefalia e meningite. O segundo sujeito é um escolar que apresenta baixa visão devido à retinopatia da prematuridade. Para o treinamento com a lupa eletrônica, os óculos e lupa manual, foram desenvolvidos materiais para aprimoramento da leitura e escrita desses sujeitos. Esses materiais consistiram em textos e questões para nortear a interpretação. É importante ressaltar que houve um preparo para que os sujeitos fossem capazes de ler 0 material produzido, isto é, a produção do material seguiu certa linearidade no que se refere à complexidade. Os sujeitos, em primeiro momento, leram palavras monossilábicas, dissilábicas, trissilábicas até que chagassem a leitura de longos textos.

DOI: 10.19146/pibic-2016-51704

\section{Conclusões}

Após todo o treinamento, verificou-se que o objetivo foi atingido, pois os sujeitos tiveram alta assistida, dado que além de aprenderam a usar os recursos ópticos e eletrônico tiveram a oportunidade de aprimorar as competências de leitura e escrita.

\section{Agradecimentos}

Agradeço ao Serviço de Apoio ao Estudante (SAE) e à professora Maria Elisabete R. F. Gasparetto pelo incentivo.
1. Haddad MAO, Sampaio MW. Estudo da Acuidade visual e da velocidade de leitura na baixa visão. In: Sampaio MW, Haddad MAO, Filho HAC, Siaulys MOC. Baixa visão e cegueira: os caminhos para a reabilitação, a educação e a inclusão. Cultura Médic

a. 2010:79-96 